\title{
HOW LIFE-HISTORY TRAITS AFFECT ECOSYSTEM PROPERTIES: EFFECTS OF DISPERSAL IN META-ECOSYSTEMS
}

\author{
F. Massol', F. Altermatt ${ }^{2,3}$, I. Gounand ${ }^{2,3}$, D. Gravel ${ }^{4,5}$, M. A. Leibold ${ }^{6}$, N. Mouquet ${ }^{7}$ \\ 1 CNRS, Université de Lille - Sciences et Technologies, UMR 8198 Evo-Eco-Paleo, SPICI group, F- \\ 59655 Villeneuve d'Ascq, France \\ 2 Department of Aquatic Ecology, Eawag, Swiss Federal Institute of Aquatic Science and \\ Technology, Überlandstrasse 133, 8600 Dübendorf, Switzerland \\ 3 Department of Evolutionary Biology and Environmental Studies, University of Zürich, \\ Winterthurerstrasse 190, CH-8057 Zürich, Switzerland \\ 4 Département de biologie, Université de Sherbrooke, 2500 Boulevard De I'Université, \\ Sherbrooke, Canada, J1K 2R1; \\ 5 Québec Center for Biodiversity Science \\ 6 Department of Integrative Biology, University of Texas at Austin, Austin, Texas, 78712. U.S.A \\ 7 UMR MARBEC (MARine Biodiversity, Exploitation and Conservation), Université de Montpellier, \\ Place Eugène Bataillon - bât 24 - CC093, 34095 Montpellier cedex 05, France
}

\begin{abstract}
The concept of life-history traits and the study of these traits are the hallmark of population biology. Acknowledging their variability and evolution has allowed us to understand how species adapt in response to their environment. The same traits are also involved in how species alter their ecosystem and shape its dynamics and functioning. Some theories, such as the metabolic theory of ecology, ecological stoichiometry or pace-of-life theory, already recognize this junction, but only do so in an implicitly non-spatial context. Meanwhile, for a decade now, it has been argued that ecosystem properties have to be understood at a larger scale using meta-ecosystem theory because source-sink dynamics, community assembly and ecosystem stability are all modified by spatial structure. Here, we argue that some ecosystem properties can be linked to a single life-history trait, dispersal, i.e. the tendency of organisms to live, compete and reproduce away from their birth place. By articulating recent theoretical and empirical studies linking ecosystem functioning and dynamics to species dispersal, we aim to highlight both the known connections between life-history traits and ecosystem properties and the unknown areas, which deserve further empirical and theoretical developments.
\end{abstract}

\section{Key words:}

community assembly; ecological stoichiometry; ecosystem functioning; metacommunity; metaecosystem; metaecosystem; productivity; source-sink dynamics; stability; synchrony 
The study of life-history traits, i.e. traits which influence part of the life cycle of organisms, has historically emerged within population biology with three main objectives: (i) understanding species adaptations to their environments through the evolution of their life cycle (initially dubbed as the study of life-history strategies, e.g. Dingle 1974, Law 1979, Strathmann 1985); (ii) making sense of systematic, apparently non-adaptive phenomena such as senescence in longlived vertebrates or plants (Hamilton 1966, Reznick et al. 2006, Baudisch et al. 2013, Lemaître et al. 2015); and (iii) connecting changes in organism life cycle with their population dynamics through models of age- and stage-structured population demographics (Charlesworth 1994, Caswell 2001). In other words, the initial perspective on life-history traits was driven mainly by evolutionary ecology and population demographics. That is, how life-history traits affect the organism.

The flip side of the issue is that life-history traits can also be related to the effect of organisms on their environment. Thanks in part to the development of ecological theories linking organism physiology to biogeochemical cycles, most notably ecological stoichiometry (Sterner and Elser 2002) and the metabolic theory of ecology (Brown et al. 2004), this initial perspective has recently shifted to incorporate ecosystem functioning and ecological network complexity (e.g. Daufresne and Loreau 2001, Berlow et al. 2009; Box 1 provides a glossary of concepts and technical terms used in this paper). For example, Enquist et al. (1999) proposed linking plant age at reproductive maturity with biomass productivity through allometric relationships between biomass growth, standing biomass and tissue/wood density. According to this theory, wood mass at plant maturity should vary as the fourth power of plant lifespan, thus allowing a rule-of-thumb to calculate the effect of additional extrinsic plant mortality on biomass production. Although empirical evidence behind theories based on allometric relationships is hard to obtain (Nee et al. 2005), it nonetheless relates life-history traits (here, age at maturity) with ecosystem functioning (here, plant productivity and carbon sequestration).

While ecological stoichiometry and the metabolic theory of ecology have revealed a number of ways that life-history can shape ecosystems (e.g. Elser et al. 2000, Berlow et al. 2009, Hall et al. 2011, Ott et al. 2014), these hypotheses lack a proper incorporation of ecological interactions (predation, competition, pollination, parasitism, etc.) and do not take the spatial structure of ecosystems into account. Other work, most notably on host-parasite interactions and the link between life-history strategies and organism immunity, have succeeded in linking life-history traits to parasitic interactions and ecosystem functioning through "pace-of-life" syndromes (Barrett et al. 2008, Réale et al. 2010, Wolf and Weissing 2012, Flick et al. 2016). While pace-of-life theory-based studies do take ecological interactions into account to explain links between lifehistory traits and ecosystem functioning, they still overlook the spatial structure of ecosystems.

More recently, metacommunity and meta-ecosystem theories have improved the general understanding of the links between the spatial structure of ecosystems and some of their properties (Loreau et al. 2003b, Leibold et al. 2004, Massol et al. 2011). These include species diversity (Mouquet and Loreau 2003, Gravel et al. 2010b), productivity (Mouquet et al. 2002b, Loreau et al. 2003a), food web interactions (Amarasekare 2008), interaction network complexity (Calcagno et al. 2011, Pillai et al. 2011) and stability (Gounand et al. 2014, Gravel et al. 2016). Nevertheless, though such theories are based on the effects of traits on the dynamics of communities, an explicit link between the metacommunity literature sensu lato and life-history theories is still lacking.

Combining metacommunity ecology with life-history trait ecology has an obvious "trait of choice": dispersal i.e. the tendency of organisms to live, compete and reproduce away from their birth place. The aim of this article is to make explicit the links that connect dispersal, as a lifehistory trait in the population biology meaning of the word (Bonte and Dahirel this issue), to meta-ecosystem properties using results obtained in the field of metacommunity/meta- 
ecosystem research. By doing so, we hope to fulfil two objectives: (i) showing how metaecosystem theory together with other theories presented above can bridge the gap between lifehistory trait studies and ecosystem properties; and (ii) identifying remaining questions that still need to be tackled in meta-ecosystem ecology to answer life-history driven questions. We identify theoretical predictions that need experimental testing, as well as needed theoretical developments, to achieve an overall and coherent understanding of natural ecosystems. Below, we first go through effects of dispersal on the functioning of meta-ecosystems. We then describe the effects of dispersal on the dynamics of ecosystems and provide an empirical overview on the life-history traits driving spatial flows between ecosystems and meta-ecosystem properties. Finally, we conclude by discussing interactions between dispersal and other life-history traits in the context of meta-ecosystem ecology, and provide perspectives for future work, both theoretical and empirical.

\section{DISPERSAL AND THE FUNCTIONING OF META-ECOSYSTEMS}

Ecosystem functioning is a broad class of properties that involve fluxes and stocks of elements, energy, nutrients or biomass among ecosystem compartments. While traditional, non-spatial ecosystem ecology considers fluxes as the result of primary production (from abiotic compartments to a biotic one), biotic interactions between species (from a biotic compartment to another one), or death and recycling of organic material (from a biotic compartment to an abiotic one), meta-ecosystem ecology acknowledges the existence of a fourth kind of flux, i.e. fluxes due to the physical movement of biotic or abiotic material from one place to another (Massol and Petit 2013). Because dispersal links the functioning of different localities, differences in dispersal can also change the functioning of the entire meta-ecosystem by increasing or decreasing total primary productivity, changing source-sink dynamics among biotic compartments or shift the distribution of biomass across food webs (Loreau and Holt 2004).

Initially studied as a natural extension of the insurance/complementarity hypothesis behind the diversity-productivity relationship (Yachi and Loreau 1999, Norberg et al. 2001), the link between species dispersal and ecosystem productivity was first made explicit for a single trophic level community in the model by Loreau et al. (2003a). The principle behind this model is quite simple: when local environments within patches fluctuate in time (but out-of-phase), dispersal allows species to average their growth rate over several patches and, hence, to perform better than if they had not dispersed. As explained in models of the evolution of dispersal in variable environments, dispersal allows fitness to depend on its arithmetic spatial average rather than geometric temporal average (Metz et al. 1983, Massol and Débarre 2015). This better performance is immediately translated as higher productivity when the species considered in such models are only primary producers (positive green arrow linking "insurance" to "primary productivity" through "temporal variability" on the right-hand side of Fig. 1).

By contrast, when the environment is spatially heterogeneous, but temporally constant, productivity decreases with dispersal (Mouquet and Loreau 2003), as dispersal maintains maladapted species through source-sink dynamics (Leibold et al. 2004; negative green arrow linking "local adaptation" to "primary productivity" through "quantitative spatial heterogeneity" on the right-hand side of Fig. 1). These results are linked to the effects of dispersal on species coexistence: in the absence of dispersal, local diversity is limited. At very high dispersal, only the best species at the regional level prevails. As a consequence, local diversity peaks at intermediate dispersal, while regional diversity decreases with dispersal (Mouquet and Loreau 2003). Both in the absence or presence of temporal fluctuations of the environment, models based on the insurance hypothesis found positive diversity-productivity relationships in metacommunities (Loreau et al. 2003a, Mouquet and Loreau 2003, Cloern 2007). 
Primary producer coexistence, and hence productivity following the insurance/complementarity hypothesis, might be improved through spatial structure, i.e. the fact that ecosystems are distinct but connected by dispersal, when producers are constrained by more than one limiting resource (ecological stoichiometry models; see Box 1 and Fig. 2). In the models of Mouquet et al. (2006) and Marleau et al. (2015), nutrient co-limitation, i.e. the "perfect case" for coexistence in the resource-ratio theory (Tilman 1982, 1988), can be obtained through spatial structure and dispersal only. In such a case, resource co-limitation does not exist locally, but emerges at a larger scale due to differences in dispersal rates among functional compartments (Fig. 2B). This emergent effect provides at the same time an explanation for increasing primary producer growth with increasing nutrient concentrations in spite of potential top-down control.

It is important to consider dispersal as a life-history trait that can have different rates among species within the ecosystem. This can affect ecosystem functioning in the same way that heterogeneity in dispersal rates has been acknowledged, namely as a force shaping species coexistence and diversity distribution within ecological communities (Amarasekare 2003, Calcagno et al. 2006, Laroche et al. 2016). For instance, Gravel et al. (2010a), found that detritus/detritivore or herbivore dispersal, but not that of the basal resource, can enhance primary productivity. Gravel et al. (2010a) also demonstrate that the expected source-sink dynamics of one compartment (e.g. plants) can be reversed when other compartments (e.g. detritus or nutrients) disperse between patches. In particular, the source-sink dynamics of primary producers are sensitive to the balance of nutrient vs. detritus diffusion; patches that would normally be unsuitable for them can become suitable when detritus diffusion rate is high enough (Gravel et al. 2010a; positive green arrow linking detritus to productivity on the left-hand side of Fig. 1).

A positive or hump-shaped relationship between dispersal and productivity can emerge due to the dual nature of dispersal (i.e. as a flux of material and energy and as a demographic rate, Massol et al. 2011, see Fig. 1). Because dispersal allows the mixing of species across space, it tends to homogenize composition among patches, and thus can have either a positive or a negative effect on productivity depending on whether environmental variability is spatial and/or temporal (Loreau et al. 2003a, Mouquet and Loreau 2003, see the link between "local adaptation"/"insurance" and "characteristics of limiting factors" in Fig. 1). By contrast, any dispersal flux of living organism eventually fuels the detritus pool in the recipient patch and, hence, fertilizes it (left-hand side arrows linking all compartments, except basal resource, to spatial heterogeneity of limiting factors on Fig. 1). Such an enrichment will increase regional productivity because (i) the recipient patch becomes suitable for primary producer if it was not in the first place, and (ii) these fluxes make resource use more efficient overall by preventing nutrient diffusion out of the meta-ecosystem (Gravel et al. 2010a, Fig. 1).

Other forms of interspecific differences may be important in mediating spatial effects on ecosystem functioning. For instance, Mouquet et al. (2013) proposed the concept of "keystone" and "burden" ecosystems, i.e. local ecosystems that have disproportionately strong positive (for keystone) or negative (for burden) impact on regional productivity. Such effects arise with spatial heterogeneity of the environment and of nutrient inputs. Keystone ecosystems are characterized by relatively high nutrient inputs and dominant primary producers that have the lowest limiting resource requirements. Because ecological stoichiometry is likely linked to demographic parameters (Klausmeier et al. 2004), which in turn have been empirically proved to be connected to life-history traits (Munoz et al. 2016), the road is not long to link interspecific variation in lifehistory traits to the "keystoneness" of ecosystems in the framework of Mouquet et al. (2013). 


\section{DISPERSAL AND THE DYNAMICS OF META-ECOSYSTEMS}

Ecosystem dynamics refers to the temporal changes of ecosystem variables (e.g. biomass of different compartments) and associated ecosystem properties (e.g. primary productivity). At least three different temporal scales can be distinguished: (i) on long time scales, a dynamical aspect of ecosystems is their assembly, i.e. the building-up of ecosystems by immigration, extinction and evolution of its component species (Morton and Law 1997); (ii) on relatively shorter time scales, the synchrony of different ecosystems connected by dispersal qualifies the coherence of different ecosystem dynamics (Koelle and Vandermeer 2005); (iii) finally, on even shorter time scales, ecosystem stability, in the sense employed by May (1972), is the tendency of systems to return to their initial state after a small perturbation. These three aspects of ecosystem dynamics are linked in complex ways (Briggs and Hoopes 2004), and, as we develop below, are sensitive to the amount of dispersal among ecosystems.

Colonisation and extinction processes are at the heart of the simplest models of ecosystem assembly. The theory of island biogeography (MacArthur and Wilson 1963) has been extended to food webs (Arii and Parrott 2004, Gravel et al. 2011, Cazelles et al. 2015, Massol et al. in press) and has revealed rich and testable predictions (i.e. how many species, trophic levels, etc. can be found on islands relatively to the mainland). These predictions arise from the interplay of two simple rules: predators colonize islands that contain at least one of their prey; and the extinction of a predator's last prey species entails its own extinction on an island. These rules result in island community assembly resembling a sampling of the mainland food web which depends on its topology (Arii and Parrott 2004). In the same way, the strength of extinction cascades triggered by a single random extinction also depend on mainland food web topology (Massol et al. in press).

In food chains, a patch-based metacommunity model predicts that transient food chain assembly within patches submitted to random perturbations depends on top-down effects of predators on prey colonisation and extinction rates (Calcagno et al. 2011). Longer food chains are more likely when predator presence decreases extinction rate and increases colonisation rate (Calcagno et al. 2011). From an evolutionary perspective, an increase of prey extinction rate due to predator occurrence increases the evolutionarily stable dispersal rate in the predator, but is unimodally linked to the evolutionarily stable dispersal rate in the prey (Pillai et al. 2012). Overall, these results suggest that food web assembly - and more generally ecosystem assembly - depends on species dispersal rates in a complex fashion, as predator-induced prey extinction tends to select for more mobility in predator than in prey. When predator presence increases prey extinction rate, foraging by the predator can have the surprising effect of both increasing maximal food chain length while decreasing the average food chain length at the metacommunity scale (Calcagno et al. 2011).

One key finding is that dispersal can substantially modify theoretical predictions of ecosystem stability. May (1972) showed with a simple model of random community matrices that complex and diverse local ecosystems are bound to be unstable. In contrast to May' conclusion, dispersal can substantially increase the stability of diverse and complex ecosystems (Gravel et al. 2016). The general principle is that dispersal tends to stabilize meta-ecosystem dynamics because it averages responses to perturbation. As a result, it buffers extremely strong interaction strengths, which are the most destabilizing. The more ecosystems are "spatially averaged" through dispersal (i.e. the more patches are connected), the more stable the meta-ecosystem can be. Numerical integration of Lotka-Volterra systems (Mougi and Kondoh 2016) and individual-based simulations (Coyte et al. 2015) lead to the same result, with the additional effect that very high dispersal tends to synchronize patch dynamics and thus to "homogenize" ecosystem responses to perturbations, 
which in turn cancels the stabilizing effect of dispersal (Gravel et al. 2016). Hence, intermediate dispersal rates provide the best conditions for species-rich meta-ecosystem stability.

The effect of dispersal on the dynamics of simple food web modules in two-patch systems, however, provides contrasting results. Predator dispersal tends to synchronize and destabilize dynamics in both predator-prey (Jansen 2001) and tri-trophic food chains (Jansen 1995). By contrast, in nutrient-detritus-primary producer-consumer systems, nutrient and detritus diffusion rates are destabilizing while producer and consumer dispersal tends to be stabilizing (Gounand et al. 2014). In the latter study, intermediate consumer dispersal rate can lead to alternative stable states of the meta-ecosystem, with the meta-ecosystem being either in a symmetrically oscillating (same dynamics in the two patches) or in an asymmetrically stable state (one patch becomes a source of producers, consumers and detritus while the other stores nutrients) without any underlying heterogeneity of the environment (Gounand et al. 2014).

\section{EMPIRICAL FEEDBACK TO THEORY}

Empirical work in ecology has been spurred by the theoretical development of the metapopulation and metacommunity concepts, which eventually led to a better understanding of natural ecosystems (e.g. Logue et al. 2011, Grainger and Gilbert 2016). We are now at the point where theoretical developments of the meta-ecosystem concept are also feeding into experimental and comparative studies (e.g. Staddon et al. 2010, Harvey et al. 2016). However, theory on meta-ecosystems is substantially more advanced than its empirical counterpart, possibly because of some inconsistencies between the general models and the specificities of natural systems (Logue et al. 2011). One such inconsistency is the functional nature of the element moving between patches, i.e. organisms dispersing vs. material flows. Another potential inconsistency comes from the type of systems that are connected, because theory focuses on fluxes among habitats of the same type, while empiricists have addressed fluxes among different habitat types (habitat is used in this section synonymously to the term biotope). We here exemplify how the meta-ecosystem concept is applied to empirical studies, and discuss this in the context of life-history traits. Based on a text-book example of possible meta-ecosystem dynamics, we identify possible disparities between the theoretical work and its empirical counterparts, and give an outlook on how to resolve the disparities and move forward.

The main focus of the metacommunity framework is the effect of dispersal on species coexistence, and the most important life-history context is with respect to decisions to disperse or not. Thus, a few dispersing individuals can often have major consequences on the connected communities. Implicitly, even in presence of intense habitat selection, it is assumed that habitats are of similar kind, e.g. different ponds connected by dispersal (Altermatt and Ebert 2010, Declerck et al. 2011). This has been paralleled by extensive experimental work on metacommunities, in which same-type habitats were connected by dispersal (e.g. Cadotte et al. 2006, Cadotte 2007, Altermatt et al. 2011, Logue et al. 2011, Grainger and Gilbert 2016). A key finding has been that the species traits related to life history, such as dispersal mode or dispersal stage induction, and life-history trade-offs can strongly affect metacommunity dynamics and species distribution (Altermatt and Ebert 2010, De Bie et al. 2012, Seymour et al. 2015). These studies, for example, found that induction of dispersal stages is linked to environmental deterioration inducing specific life-history stages (dispersal stages), and eventually affecting species' spatial distribution (Altermatt and Ebert 2010, De Bie et al. 2012). Trade-offs between competitive ability and dispersal ability result in distributions of species differing from neutral models assuming otherwise identical life-history traits (Seymour et al. 2015).

The meta-ecosystem framework explicitly considers local nutrient dynamics and material flows such that dispersing organisms can also be seen as vectors of resources flowing across units of 
spatial organisation. The theoretical work on meta-ecosystems is indifferent with respect to the identity of these habitat types. Empirically, however, there are two major and distinct scenarios: First, the patches may be of the same habitat type, which would then be an extension of the metacommunity but in which resource flows are also added, e.g. exchange of dispersers and resources among different ponds in a wetland (Howeth and Leibold 2010), intertidal communities (Menge et al. 2015), or litter windblown across different agroecosystems (Shen et al. 2011). The second scenario, and possibly the most common one, however, is that the flows are between different habitat types, such as resource flows between pelagic and benthic habitats, and - more strikingly - between terrestrial and aquatic ecosystems. Massive spatial flows can occur between contrasting ecosystems (Polis et al. 1997) and they are often linked to species life-history, whereby species either transport resources during foraging (e.g. seabirds on islands, Polis and Hurd 1995) or migration, such as excretion of foraging fishes (Bray et al. 1981, Schindler and Scheuerell 2002, Vanni 2002) or feces of larges herbivores or migratory birds (Bazely and Jefferies 1985, Seagle 2003, Jefferies et al. 2004), or cadavers that serve as resources in the recipient ecosystem without having a population dynamics (e.g. migrating aquatic species in streams, Helfield and Naiman 2002, Naiman et al. 2002, Muehlbauer et al. 2014). Dispersal in the strict sense (Massol et al. 2011) may actually be not feasible between different habitat types for most organisms, as they can only live in one of these habitats and die in the other one. In such a situation, material flows would be the predominant exchange. Thus, in many empirical systems, these material flows are causally linked to the death of organisms (Nakano and Murakami 2001, Sitters et al. 2015), and thus directly depend on life span as one of the most important life-history aspects.

Most of the empirical examples of strong meta-ecosystem dynamics involve aquatic-terrestrial linkages, in which spatial flows relax each other ecosystem's limitations, e.g. terrestrial carbon input into carbon-limited aquatic systems and converse subsidy of the terrestrial system with aquatic nitrogen (Sitters et al. 2015). A textbook example thereof would be emerging aquatic insects, which can be accidentally diverted into terrestrial systems during their metamorphosis to adulthood and reproductive flights, and subsequently die. Importantly, these organisms, even if moving and mating in the recipient ecosystem, oviposit in the donor ecosystem (aquatic habitat) and do not always actively participate in consumer-resource dynamics in the recipient ecosystem (terrestrial habitat) contrary to what meta-ecosystem models assume regarding organism flows. Flows of aquatic organisms serving as resources in terrestrial systems have been extensively described for aquatic insects but also fish dying after spawning (e.g. Naiman et al. 2002, Muehlbauer et al. 2014, Sitters et al. 2015). However, these studies on strong spatial couplings between ecosystems are mostly found in the ecosystem ecology field literature, with observational data either predating or only marginally linked to the theoretical concept of metaecosystems, which historically emerged from the field of population and community ecology (Loreau et al. 2003b).

In contrast, experimental work on meta-ecosystems has been developed from classic experimental approaches used for metacommunities (Logue et al. 2011, Grainger and Gilbert 2016, Smeti et al. 2016). Such meta-ecosystem experiments have been done almost exclusively using patches of the same type of ecosystem (but see Venail et al. 2008 for an example of microbial communities replicated on different carbon sources), including both dispersal and mass-flows of resources (e.g. Howeth and Leibold 2010, Staddon et al. 2010, Legrand et al. 2012, Livingston et al. 2012). These experiments confirm theoretical predictions that meta-ecosystem dynamics can emerge from feedbacks between organism dispersal and resource dynamics in same habitat-type coupled systems, analogous to meta-ecosystem models (first scenario in Fig. 3), such as lake or island networks, or forest patches in an agricultural matrix. However, the important effects that may arise in the emblematic case studies of couplings between ecosystems of different habitat types (second scenario in Fig. 3) have yet to be adequately modelled or experimentally tested. 
Overall, feedback of empirical observations to meta-ecosystem theory leads to the conclusion that the drivers of meta-ecosystem dynamics may differ depending on the scenario of habitat types involved (Fig. 3). In same-habitat-type meta-ecosystems, the spatial structure could be seen as metacommunity-like, with organism dispersal as the dominant spatial flow type, and metaecosystem effects would mainly emerge from interactions between dispersal and local resource dynamics (including local recycling). In different-habitat-type meta-ecosystems (e.g. aquaticterrestrial coupling), the spatial structure mostly consists of material flows (dead organisms with negligible true dispersal), and meta-ecosystem effects would emerge from interactions between material flows and local community dynamics. In the first case, spatial couplings arise from species dispersal traits, while in the second it arises from phenology and life span history-traits.

We propose that this distinction allows a better identification of the empirical and theoretical work needed: for same-habitat-type meta-ecosystems, we lack observational data to adequately quantify resource flows and we therefore do not yet understand their significance for local dynamics. For different-habitat type meta-ecosystems, flows are well documented, but theoretical models that address the role of organisms which are not dispersing between patches but are instead crossing the barriers to fuel recipient resource pools. In pioneering modelling work, Leroux and Loreau (2012) opened the field by investigating the effects of cross-ecosystem pulsed-flows of herbivores as preys, but further developments in this direction are still needed. On the experimental side, technical challenges have to be addressed to causally separate spatial flows of materials (resources) from spatial flows of organisms (dispersers) (e.g. Harvey et al. 2016) in order to be able to test precise meta-ecosystem mechanisms. Empirical questions emerging from this scenario are to test how species life-history traits in one habitat type may cascade to other habitat types through material flows. Furthermore, experimental tests disentangling interactions between perturbation regimes and spatial flows of resources may be highly relevant from an applied empirical perspective, and can be addressed in an explicit metaecosystem perspective. Ultimately, we expect the dynamic interplay of theory (e.g. Loreau et al. 2003b, Massol et al. 2011, Gounand et al. 2014) and empirical work to lead to a better and more mechanistic understanding of spatial community and ecosystems dynamics.

\section{Discussion}

\section{Dispersal: a life-history trait with many effects on ecosystems}

Previous sections have emphasized some ecosystem properties that are affected by dispersal within meta-ecosystems. First, depending on species coexistence mechanisms, dispersal tends to increase local diversity and to increase meta-ecosystem productivity, at least until intermediate levels of dispersal (Levin 1974, Mouquet and Loreau 2002, Loreau et al. 2003a, Economo and Keitt 2008). Second, provided patches are sufficiently heterogeneous in their response to perturbations, dispersal stabilizes meta-ecosystem dynamics (Gravel et al. 2016, Mougi and Kondoh 2016), although the dispersal of some trophic levels is more stabilizing than others (Gounand et al. 2014). Third, in simple interaction networks, dispersal tends to synchronize and destabilize local dynamics (Jansen 1995, 2001) while limited dispersal increases persistence of otherwise ephemeral species assemblages (Briggs and Hoopes 2004). Fourth, in spatially structured heterogeneous ecosystems, dispersal paves the way for nutrient co-limitation and hence for species coexistence on a few limiting resources (Mouquet et al. 2006, Marleau et al. 2015). On top of these effects of dispersal on ecosystem functioning and dynamics, species dispersal/colonization abilities shape food web complexity (Calcagno et al. 2011, Pillai et al. 2011), which can potentially feedback on ecosystem stability (Allesina and Tang 2012, Neutel and Thorne 2014, Grilli et al. 2016). 
Meta-ecosystem theory is not solely geared towards understanding the functioning of ecosystems, but also grounded in the foundations laid out by metapopulation and metacommunity theories. Therefore, the movements of species within a meta-ecosystem are bound to be governed by how organisms perceive their environment and where they thrive - i.e. non-random dispersal, habitat selection, foraging and dispersal evolution (Amarasekare 2008). The feedback of meta-ecosystem state on dispersal evolution has just begun to be studied, and has focused so far on simple predator-prey configurations (Chaianunporn and Hovestadt 2012, Pillai et al. 2012, Drown et al. 2013, Travis et al. 2013, Amarasekare 2015). On top of all the mechanisms of dispersal evolution that are already known (Bowler and Benton 2005, Ronce 2007, Duputié and Massol 2013), meta-ecosystem context is likely to provide new selection mechanisms through the discrepancy in generation time and spatial scale of motility of different trophic levels. For instance, dispersal is selected against when environmental quality of habitat patches is positively autocorrelated in time, but selected for when it is positively autocorrelated in space (Travis 2001, Massol and Débarre 2015). In the case of a prey species for which predator presence is an "environmental characteristic", as predators live longer, have slower population dynamics and can cover and forage over several prey patches at once, the "effective" autocorrelation of the environment for the prey will likely be positive in both time and space, thus affecting the evolution of prey dispersal. Evolution of dispersal in food webs also imposes a feedback between the cost of dispersal and dispersal itself, as sparse prey populations can diminish predation pressure and, hence, decrease the cost of dispersal borne out of predation between habitat patches. Finally, it is also noteworthy that, even though dispersal evolution has begun being considered in a food web context, the consequences of this evolution on ecosystem functioning have yet to be studied.

\section{Other life-history traits and their impact on meta-ecosystems} patterns that would otherwise require more complicated theories to explain, such as the maintenance of maladapted species (the "mass effect" paradigm of metacommunity theory, Shmida and Wilson 1985, Leibold et al. 2004) or the distribution of species abundance in ecological samples, as predicted by the neutral theory of ecology (Hubbell 2001, Volkov et al. 2003). From this central tenet, it is no wonder that the main connection made by these studies between life-history traits and ecosystem properties considers dispersal as the life-history trait of interest. However, dispersal generally correlates with a wide palette of other traits (e.g. fecundity, body size, etc., see Bonte and Dahirel this issue), known collectively as "dispersal syndromes" (Clobert et al. 2009, Ronce and Clobert 2012, Duputié and Massol 2013). Such correlations can be explained in three ways: (i) the other trait correlates with dispersal ability because there is a trade-off constraining the values of both traits (e.g. time allocation trade-off preventing an organism from both moving and eating at the same time); (ii) dispersal correlates with the other trait because both traits are structurally linked, e.g. they both scale with organism size (allometric link) or they both respond similarly to biological stoichiometric changes (stoichiometric link); (iii) both dispersal and the other trait are shaped by joint selective pressures, with either the same pressures acting on both traits at once (e.g. dormancy and dispersal, Vitalis et al. 2013) or one or both trait(s) having a selective feedback on the other (e.g. selfing and dispersal, Cheptou and Massol 2009, or local adaptation and dispersal, Berdahl et al. 2015). In practice, correlations between dispersal and other life-history traits can only be uncovered when there is sufficient variation in the traits under study, which means that the wider "the phylogenetic net", the easier it is to capture such correlations. However, interpreting these correlations as resulting from trade-offs, structural constraints or joint evolution is often difficult and experimentally challenging, especially when the problem is framed as the inference of lifehistory invariants (Nee et al. 2005). 
It would be difficult to enumerate here all the possibilities of dispersal-trait correlations that would likely have impacts on meta-ecosystem functioning and dynamics. Some of these have already been considered separately. For example, Otto et al. (2007)'s study on the effect of predator-prey body mass ratios on food web stability could be easily coupled with Gravel et al. (2016)'s study on the effect of dispersal on ecosystem stability to gain insight into the combined effects of dispersal and body size when both traits are structurally linked. Others readily lend themselves to speculation. For example, with higher passive dispersal in smaller organisms and the relationship between initial growth, asymptotic size and temperature in ectotherms (Atkinson et al. 2006), one is tempted to think that warming oceans might become less connected by dispersal, as some data on larval dispersal already suggest (O'Connor et al. 2007), which in turn would affect their functioning and dynamics as predicted by the models described in previous sections.

An especially challenging issue regarding life-history trait evolution and meta-ecosystem properties is to link ecological stoichiometry with ecosystem properties through cell and organism physiology (Jeyasingh and Weider 2007), e.g. as proteins and rRNA have different stoichiometry (Loladze and Elser 2011). For instance, the proportion of phosphorus content due to RNA (vs. due to skeleton) is expected to decrease with body mass in vertebrates (Gillooly et al. 2005). In some insects, high-dispersal genotypes are associated with particular alleles at genes coding for phosphoglucose isomerase (PGI), e.g. in the Glanville fritillary butterfly (Haag et al. 2005, Hanski and Saccheri 2006). Efficient PGl genotypes have a higher peak metabolic rate and fly longer than less efficient types (Niitepõld et al. 2009, Niitepõld and Hanski 2013). As the PGI enzyme is involved in glycolysis and gluconeogenesis, a link between PGI and ecological stoichiometry might be expected (as suggested by experimental evidence on Daphnia pulex, Jeyasingh and Weider 2005, Weider et al. 2005) which, in turn, would link ecological stoichiometry with dispersal ability. This field of inquiry is just beginning, but might reveal exceptional findings linking traits and ecosystem functioning, such as an increased spatial diffusion of one type of nutrient over another one due to a systematic association of body stoichiometry with dispersal rate.

\section{Challenges ahead for meta-ecosystem ecology}

The study - both theoretical and empirical - of mechanisms linking organism dispersal and ecosystem properties is a recent endeavour in ecology. To date, meta-ecosystem ecology has focused on linking community ecology (species coexistence, distribution of diversity), with ecological dynamics and demographics (ecosystem stability, synchrony, assembly), ecological interaction networks (network complexity, material/energy fluxes) and functional ecology (stocks, fluxes and productivity). However, two interfaces have yet to be strengthened with respect to life-history traits and meta-ecosystem properties.

First, the integration of biogeography and functional ecology through meta-ecosystems has only begun to be addressed (Wieters et al. 2008, Meynard et al. 2011, Kissling et al. 2012, Nogales et al. 2015). This interface between meta-ecosystem ecology and biogeography is a necessary step if we are to extend species distribution models and other map-based representations of biodiversity to map-based representations of ecosystem functioning and linking these with the underlying mechanisms involved. As life-history traits play key roles in determining species response to anthropically driven changes of the environment (Lindborg 2007, Colautti et al. 2010, Ojanen et al. 2013), life-history traits, and dispersal in particular, will probably play a key role in explaining spatial distribution of ecosystem functioning.

Second, we can ask whether variability in life-history traits such as dispersal may entail direct consequences for ecosystem properties. For instance, Laroche et al. (2016) recently studied the 
evolution of dispersal in a model based on Hubbell's (2001) neutral model of biodiversity to assess whether species would converge or diverge in dispersal rate. As it turned out, diversity patterns are strongly altered by disruptive selection on dispersal (Laroche et al. 2016). Speculation linking these results with others from meta-ecosystem models (e.g. Gounand et al. 2014) may lead us to think heterogeneous selection on dispersal rates among trophic levels could drive ecoevolutionary feedbacks linking dispersal evolution and ecosystem functioning.

\section{Closing words: empirical and theoretical directions}

We list here several important directions that deserve further enquiry, both on the empirical and theoretical fronts. Meta-ecosystem ecology and its interface with life-history studies in particular need to be strengthened by making experiments to test important meta-ecosystem predictions and by developing meta-ecosystem models in directions that will more strongly link them to lifehistory traits:

(i) The maximization of ecosystem productivity at intermediate dispersal has to be tested with respect to the mechanisms maintaining coexistence of primary producers (Mouquet et al. 2002a, but see Howeth and Leibold 2008), and the effect of dispersal asymmetries between trophic levels on productivity (Gravel et al. 2010a) needs experimental support.

(ii) Experimental studies are required to explore whether different ecosystem functions are affected differently by the movements of nutrients, detritus, primary producers, consumers, etc. Existing models suggest that dispersal asymmetries can do more than just alter patch source-sink status (Gounand et al. 2014) and existing experiments point out possible effects of basal species dispersal on species regulation processes (Howeth and Leibold 2008).

(iii) The general prediction that intermediate dispersal rates should stabilize meta-ecosystems has to be tested properly, both experimentally (but see Howeth and Leibold 2010, 2013), and based on large-scale observational datasets of abundance time series (following the approach of Jacquet et al. 2016).

(iv) The idea of spatial complementarity between habitats within a meta-ecosystem needs to be assessed and experimentally challenged. For instance, when ecosystems are intrinsically limited by different nutrients in different habitats (e.g. $\mathrm{C}$ in aquatic habitats vs. $\mathrm{N}$ in terrestrial ones), experiments are needed to assess whether intermediate (or high) spatial flows of biotic compartments lead to higher productivity.

(v) Experiments should test whether spatial structure and heterogeneity of supply points can lead to the stable coexistence of species with different resource ratios (Mouquet et al. 2006, Marleau et al. 2015), possibly exploring situations more complicated than two-patch, twospecies, two-resource systems.

(vi) Theoretical studies are needed to explore how perturbations propagate within a metaecosystem, depending on which compartments are dispersing more, on connectivity patterns, on first-disturbed compartments and on the nature of the perturbation (invasion, extinction, habitat destruction, etc.), following new perspectives on the notion of stability in ecology (Arnoldi et al. 2016).

(vii) One promising theoretical endeavour would be to predict the impact of ecosystem removals on diversity and functioning in a spatially explicit fashion, thus merging models of Economo and Keitt $(2008,2010)$ on diversity in metacommunity networks and Mouquet et al. (2013) on keystone ecosystems.

(viii)Species coevolution models are highly needed to assess whether evolution leads to increases or decreases in productivity, fluxes, synchronicity, stability, etc. at the meta-ecosystem scale, e.g. focusing on the evolution of dispersal at different trophic levels within food webs.

(ix) Models of ecosystem assembly and disassembly should be developed to assess the conditions of existence of "forks" (i.e. alternative trajectories), "dead-ends" or loops in the topology of ecosystem successions (Law and Morton 1993). 


\section{ACKNOWLEDGEMENTS}

We thank D. Bonte for organizing this special issue and allowing FM to present the idea of the paper at the Nordic Oikos Society meeting in Turku, February 2016. We thank three anonymous reviewers and Dries Bonte for insightful comments on an earlier version of the manuscript. FM was supported by the CNRS and through the ANR-funded project ARSENIC (ANR-14-CE02-0012). DG was supported by the NSERC and the Canada Research Chair Program. MAL was supported by NSF-DEB 1353919. NM was supported by the CNRS. FA and IG were supported by Swiss National Science Foundation Grant PPooP3_150698, University of Zurich and Eawag.

This work was inspired by early discussions between FM, DG and MAL at the "Stoichiometry in meta-ecosystems" working group at the National Institute for Mathematical and Biological Synthesis, sponsored by the National Science Foundation, the U.S. Department of Homeland Security, and the U.S. Department of Agriculture through NSF Award \#EF-0832858, with additional support from The University of Tennessee, Knoxville.

\section{REFERENCES}

Abrams, P. A. and W. G. Wilson. 2004. Coexistence of competitors in metacommunities due to spatial variation in resource growth rates; does $\mathrm{R}^{*}$ predict the outcome of competition? Ecology Letters 7:929-940.

Allesina, S. and S. Tang. 2012. Stability criteria for complex ecosystems. Nature 483:205-208.

Altermatt, F. and D. Ebert. 2010. Populations in small, ephemeral habitat patches may drive dynamics in a Daphnia magna metapopulation. Ecology 91:2975-2982.

Altermatt, F., S. Schreiber, and M. Holyoak. 2011. Interactive effects of disturbance and dispersal directionality on species richness and composition in metacommunities. Ecology 92:859870.

Amarasekare, P. 2003. Competitive coexistence in spatially structured environments: a synthesis. Ecology Letters 6:1109-1122.

Amarasekare, P. 2008. Spatial dynamics of foodwebs. Annual Review of Ecology Evolution and Systematics 39:479-500.

Amarasekare, P. 2015. Evolution of dispersal in a multi-trophic community context. Oikos:n/a-n/a.

Amarasekare, P. and R. M. Nisbet. 2001. Spatial heterogeneity, source-sink dynamics, and the local coexistence of competing species. American Naturalist 158:572-584.

Arii, K. and L. Parrott. 2004. Emergence of non-random structure in local food webs generated from randomly structured regional webs. Journal of Theoretical Biology 227:327-333.

Arnoldi, J. F., M. Loreau, and B. Haegeman. 2016. Resilience, reactivity and variability: A mathematical comparison of ecological stability measures. Journal of Theoretical Biology 389:47-59.

Atkinson, D., S. A. Morley, and R. N. Hughes. 2006. From cells to colonies: at what levels of body organization does the 'temperature-size rule' apply? Evolution \& Development 8:202-214.

Barrett, L. G., P. H. Thrall, J. J. Burdon, and C. C. Linde. 2008. Life history determines genetic structure and evolutionary potential of host-parasite interactions. Trends in Ecology \& Evolution 23:678-685.

Baudisch, A., R. Salguero-Gómez, O. R. Jones, T. Wrycza, C. Mbeau-Ache, M. Franco, and F. Colchero. 2013. The pace and shape of senescence in angiosperms. Journal of Ecology 101:596-606.

Bazely, D. R. and R. L. Jefferies. 1985. Goose faeces: a source of nitrogen for plant growth in a grazed salt marsh. Journal of Applied Ecology 22:693-703.

Begon, M., C. R. Townsend, and J. L. Harper. 2006. Ecology: From individuals to ecosystems. Fourth edition edition. Blackwell publishing, Oxford.

Berdahl, A., C. J. Torney, E. Schertzer, and S. A. Levin. 2015. On the evolutionary interplay between dispersal and local adaptation in heterogeneous environments. Evolution 69:1390-1405. 
Berlow, E. L., J. A. Dunne, N. D. Martinez, P. B. Stark, R. J. Williams, and U. Brose. 2009. Simple prediction of interaction strengths in complex food webs. Proceedings of the National Academy of Sciences 106:187-191.

Bonte, D. and M. Dahirel. this issue. Dispersal: a central trait in life history. Oikos.

Bowler, D. E. and T. G. Benton. 2005. Causes and consequences of animal dispersal strategies: relating individual behaviour to spatial dynamics. Biological Reviews 80:205-225.

Bray, R. N., A. C. Miller, and G. G. Geesey. 1981. The fish connection: a trophic link between planktonic and rocky reef communities. Science 214:204-205.

Briggs, C. J. and M. F. Hoopes. 2004. Stabilizing effects in spatial parasitoid-host and predatorprey models: a review. Theoretical Population Biology 65:299-315.

Brown, J. H., J. F. Gillooly, A. P. Allen, V. M. Savage, and G. B. West. 2004. Toward a metabolic theory of ecology. Ecology 85:1771-1789.

Cadotte, M. W. 2007. Competition-colonization trade-offs and disturbance effects at multiple scales. Ecology 88:823-829.

Cadotte, M. W., D. V. Mai, S. Jantz, M. D. Collins, M. Keele, and J. A. Drake. 2006. On Testing the Competition-Colonization Trade-Off in a Multispecies Assemblage. American Naturalist 168:704-709.

Calcagno, V., F. Massol, N. Mouquet, P. Jarne, and P. David. 2011. Constraints on food chain length arising from regional metacommunity dynamics. Proceedings of the Royal Society of London B Biological Sciences 278:3042-3049.

Calcagno, V., N. Mouquet, P. Jarne, and P. David. 2006. Coexistence in a metacommunity: the competition-colonization trade-off is not dead. Ecology Letters 9:897-907.

Caswell, H. 2001. Matrix Population Models: Construction, Analysis, and Interpretation, Second edition. 2nd edition. Sinauer Associates, Inc. Publishers, Sunderland, Massachussets.

Cazelles, K., N. Mouquet, D. Mouillot, and D. Gravel. 2015. On the integration of biotic interaction and environmental constraints at the biogeographical scale. Ecography 39:921-931.

Chaianunporn, T. and T. Hovestadt. 2012. Evolution of dispersal in metacommunities of interacting species. Journal of Evolutionary Biology 25:2511-2525.

Charlesworth, B. 1994. Evolution in age-structured populations, Second edition. 2nd edition. Cambridge University Press, Cambridge.

Cheptou, P.-O. and F. Massol. 2009. Pollination fluctuations drive evolutionary syndromes linking dispersal and mating system. American Naturalist 174:46-55.

Clobert, J., J.-F. Le Galliard, J. Cote, S. Meylan, and M. Massot. 2009. Informed dispersal, heterogeneity in animal dispersal syndromes and the dynamics of spatially structured populations. Ecology Letters 12:197-209.

Cloern, J. E. 2007. Habitat connectivity and ecosystem productivity: Implications from a simple model. American Naturalist 169:E21-E33.

Colautti, R. I., C. G. Eckert, and S. C. H. Barrett. 2010. Evolutionary constraints on adaptive evolution during range expansion in an invasive plant. Proceedings of the Royal Society B: Biological Sciences 277:1799-1806.

Coyte, K. Z., J. Schluter, and K. R. Foster. 2015. The ecology of the microbiome: Networks, competition, and stability. Science 350:663-666.

Daufresne, T. and L. O. Hedin. 2005. Plant coexistence depends on ecosystem nutrient cycles: Extension of the resource-ratio theory. Proceedings of the National Academy of Sciences of the United States of America 102:9212-9217.

Daufresne, T. and M. Loreau. 2001. Plant-herbivore interactions and ecological stoichiometry: when do herbivores determine plant nutrient limitation? Ecology Letters 4:196-206.

De Bie, T., L. De Meester, L. Brendonck, K. Martens, B. Goddeeris, D. Ercken, H. Hampel, L. Denys, L. Vanhecke, K. Van der Gucht, J. Van Wichelen, W. Vyverman, and S. A. J. Declerck. 2012. Body size and dispersal mode as key traits determining metacommunity structure of aquatic organisms. Ecology Letters 15:740-747. 
Declerck, S. A. J., J. S. Coronel, P. Legendre, and L. Brendonck. 2011. Scale dependency of processes structuring metacommunities of cladocerans in temporary pools of High-Andes wetlands. Ecography 34:296-305.

Dingle, H. 1974. The experimental analysis of migration and life-history strategies in insects. Pages 329-342 Experimental Analysis of Insect Behaviour. Springer.

Drown, D. M., M. F. Dybdahl, and R. Gomulkiewicz. 2013. Consumer-resource interactions and the evolution of migration. Evolution 67:3290-3304.

Duputié, A. and F. Massol. 2013. An empiricist's guide to theoretical predictions on the evolution of dispersal. Interface Focus 3:20130028.

Economo, E. P. and T. H. Keitt. 2008. Species diversity in neutral metacommunities: a network approach. Ecology Letters 11:52-62.

Economo, E. P. and T. H. Keitt. 2010. Network isolation and local diversity in neutral metacommunities. Oikos 119:1355-1363.

Edelaar, P. and D. I. Bolnick. 2012. Non-random gene flow: an underappreciated force in evolution and ecology. Trends in Ecology \& Evolution 27:659-665.

Elser, J. J., R. W. Sterner, E. Gorokhova, W. F. Fagan, T. A. Markow, J. B. Cotner, J. F. Harrison, S. E. Hobbie, G. M. Odell, and L. J. Weider. 2000. Biological stoichiometry from genes to ecosystems. Ecology Letters 3:540-550.

Enquist, B. J., G. B. West, E. L. Charnov, and J. H. Brown. 1999. Allometric scaling of production and life-history variation in vascular plants. Nature 401:907-911.

Flick, A. J., M. A. Acevedo, and B. D. Elderd. 2016. The negative effects of pathogen-infected prey on predators: a meta-analysis. Oikos:n/a-n/a.

Gillooly, J. F., A. P. Allen, J. H. Brown, J. J. Elser, C. M. del Rio, V. M. Savage, G. B. West, W. H. Woodruff, and H. A. Woods. 2005. The metabolic basis of whole-organism RNA and phosphorus content. Proceedings of the National Academy of Sciences of the United States of America 102:11923-11927.

Gounand, I., N. Mouquet, E. Canard, F. Guichard, C. Hauzy, and D. Gravel. 2014. The Paradox of enrichment in metaecosystems. The American Naturalist 184:752-763.

Grainger, T. N. and B. Gilbert. 2016. Dispersal and diversity in experimental metacommunities: linking theory and practice. Oikos:n/a-n/a.

Gravel, D., F. Guichard, M. Loreau, and N. Mouquet. 2010a. Source and sink dynamics in metaecosystems. Ecology 91:2172-2184.

Gravel, D., F. Massol, E. Canard, D. Mouillot, and N. Mouquet. 2011. Trophic theory of island biogeography. Ecology Letters 14:1010-1016.

Gravel, D., F. Massol, and M. A. Leibold. 2016. Stability and complexity in model meta-ecosystems. Nature Communications 7:12457.

Gravel, D., N. Mouquet, M. Loreau, and F. Guichard. 2010b. Patch dynamics, persistence and species coexistence in metaecosystems. American Naturalist 176:289-302.

Grilli, J., T. Rogers, and S. Allesina. 2016. Modularity and stability in ecological communities. Nat Commun 7.

Grover, J. P. and R. D. Holt. 1998. Disentangling resource and apparent competition: realistic models for plant-herbivore communities. Journal of Theoretical Biology 191:353-376.

Haag, C. R., M. Saastamoinen, J. H. Marden, and I. Hanski. 2005. A candidate locus for variation in dispersal rate in a butterfly metapopulation. Proceedings of the Royal Society of London B Biological Sciences 272:2449-2456.

Hall, E. K., F. Maixner, O. Franklin, H. Daims, A. Richter, and T. Battin. 2011. Linking Microbial and Ecosystem Ecology Using Ecological Stoichiometry: A Synthesis of Conceptual and Empirical Approaches. Ecosystems 14:261-273.

Hamilton, W. D. 1966. The moulding of senescence by natural selection. Journal of Theoretical Biology 12:12-45.

Hanski, I. and I. Saccheri. 2006. Molecular-level variation affects population growth in a butterfly metapopulation. PLoS Biology 4:719-726. 
Harvey, E., I. Gounand, P. Ganesanandamoorthy, and F. Altermatt. 2016. Spatially cascading effect of perturbations in experimental meta-ecosystems. Proceedings of the Royal Society B: Biological Sciences 283.

Helfield, J. M. and R. J. Naiman. 2002. Salmon and alder as nitrogen sources to riparian forests in a boreal Alaskan watershed. Oecologia 133:573-582.

Howeth, J. G. and M. A. Leibold. 2008. Planktonic dispersal dampens temporal trophic cascades in pond metacommunities. Ecology Letters 11:245-257.

Howeth, J. G. and M. A. Leibold. 2010. Species dispersal rates alter diversity and ecosystem stability in pond metacommunities. Ecology 91:2727-2741.

Howeth, J. G. and M. A. Leibold. 2013. Predation inhibits the positive effect of dispersal on intraspecific and interspecific synchrony in pond metacommunities. Ecology 94:2220-2228.

Hubbell, S. P. 2001. The Unified Neutral Theory of Biodiversity and Biogeography. Princeton University Press, Princeton.

Jacquet, C., C. Moritz, L. Morissette, P. Legagneux, F. Massol, P. Archambault, and D. Gravel. 2016. No complexity-stability relationship in empirical ecosystems Nature Communications 7:12573.

Jansen, V. A. A. 1995. Effects of dispersal in a tri-trophic metapopulation model. Journal of Mathematical Biology 34:195-224.

Jansen, V. A. A. 2001. The dynamics of two diffusively coupled predator-prey populations. Theoretical Population Biology 59:119-131.

Jefferies, R. L., R. F. Rockwell, and K. F. Abraham. 2004. Agricultural food subsidies, migratory connectivity and large-scale disturbance in Arctic coastal systems: a case study. Integrative and Comparative Biology 44:130.

Jeyasingh, P. D. and L. J. Weider. 2005. Phosphorus availability mediates plasticity in life-history traits and predator-prey interactions in Daphnia. Ecology Letters 8:1021-1028.

Jeyasingh, P. D. and L. J. Weider. 2007. Fundamental links between genes and elements: evolutionary implications of ecological stoichiometry. Molecular Ecology 16:4649-4661.

Kissling, W. D., C. F. Dormann, J. Groeneveld, T. Hickler, I. Kühn, G. J. McInerny, J. M. Montoya, C. Römermann, K. Schiffers, F. M. Schurr, A. Singer, J.-C. Svenning, N. E. Zimmermann, and R. B. O'Hara. 2012. Towards novel approaches to modelling biotic interactions in multispecies assemblages at large spatial extents. Journal of Biogeography 39:2163-2178.

Klausmeier, C. A., E. Litchman, T. Daufresne, and S. A. Levin. 2004. Optimal nitrogen-tophosphorus stoichiometry of phytoplankton. Nature 429:171-174.

Koelle, K. and J. Vandermeer. 2005. Dispersal-induced desynchronization: from metapopulations to metacommunities. Ecology Letters 8:167-175.

Laroche, F., P. Jarne, T. Perrot, and F. Massol. 2016. The evolution of the competition-dispersal trade-off affects $\alpha$ - and $\beta$-diversity in a heterogeneous metacommunity. Proceedings of the Royal Society of London B: Biological Sciences 283:20160548.

Law, R. 1979. Optimal life histories under age-specific predation. The American Naturalist 114:399417.

Law, R. and R. D. Morton. 1993. Alternative permanent states of ecological communities. Ecology:1347-1361.

Legrand, D., O. Guillaume, M. Baguette, J. Cote, A. Trochet, O. Calvez, S. Zajitschek, F. Zajitschek, J. Lecomte, Q. Bénard, J.-F. Le Galliard, and J. Clobert. 2012. The Metatron: an experimental system to study dispersal and metaecosystems for terrestrial organisms. Nature Methods 9:828-834.

Leibold, M. A. 1995. The niche concept revisited: mechanistic models and community context. Ecology 76:1371-1382.

Leibold, M. A., M. Holyoak, N. Mouquet, P. Amarasekare, J. M. Chase, M. F. Hoopes, R. D. Holt, J. B. Shurin, R. Law, D. Tilman, M. Loreau, and A. Gonzalez. 2004. The metacommunity concept: a framework for multi-scale community ecology. Ecology Letters 7:601-613. 
Lemaître, J.-F., V. Berger, C. Bonenfant, M. Douhard, M. Gamelon, F. Plard, and J.-M. Gaillard. 2015. Early-late life trade-offs and the evolution of ageing in the wild. Proceedings of the Royal Society Biological Sciences Series B 282.

León, J. A. and D. B. Tumpson. 1975. Competition between two species for two complementary or substitutable resources. Journal of Theoretical Biology 50:185-201.

Leroux, S. J. and M. Loreau. 2012. Dynamics of reciprocal pulsed subsidies in local and metaecosystems. Ecosystems 15:48-59.

Levin, S. A. 1974. Dispersion and population interactions. The American Naturalist 108:207-228.

Lindborg, R. 2007. Evaluating the distribution of plant life-history traits in relation to current and historical landscape configurations. Journal of Ecology 95:555-564.

Livingston, G., M. Matias, V. Calcagno, C. Barbera, M. Combe, M. A. Leibold, and N. Mouquet. 2012. Competition-colonization dynamics in experimental bacterial metacommunities. Nat Commun 3:1234.

Logue, J. B., N. Mouquet, H. Peter, H. Hillebrand, and The Metacommunity Working Group. 2011. Empirical approaches to metacommunities: a review and comparison with theory. Trends in Ecology and Evolution 26:482-491.

Loladze, I. and J. J. Elser. 2011. The origins of the Redfield nitrogen-to-phosphorus ratio are in a homoeostatic protein-to-rRNA ratio. Ecology Letters 14:244-250.

Loreau, M. and R. D. Holt. 2004. Spatial flows and the regulation of ecosystems. American Naturalist 163:606-615.

Loreau, M., N. Mouquet, and A. Gonzalez. 2003a. Biodiversity as spatial insurance in heterogeneous landscapes. Proceedings of the National Academy of Sciences of the United States of America 100:12765-12770.

Loreau, M., N. Mouquet, and R. D. Holt. 2003b. Meta-ecosystems: a theoretical framework for a spatial ecosystem ecology. Ecology Letters 6:673-679.

MacArthur, R. H. and E. O. Wilson. 1963. An equilibrium theory of insular zoogeography. Evolution 17:373-387.

Marleau, J. N., F. Guichard, and M. Loreau. 2015. Emergence of nutrient co-limitation through movement in stoichiometric meta-ecosystems. Ecology Letters 18:1163-1173.

Massol, F. and F. Débarre. 2015. Evolution of dispersal in spatially and temporally variable environments: the importance of life cycles. Evolution 69:1925-1937.

Massol, F., M. Dubart, V. Calcagno, K. Cazelles, C. Jacquet, S. Kéfi, and D. Gravel. in press. Island biogeography of food webs. Advances in Ecological Research 56.

Massol, F., D. Gravel, N. Mouquet, M. W. Cadotte, T. Fukami, and M. A. Leibold. 2011. Linking ecosystem and community dynamics through spatial ecology. Ecology Letters 14:313-323.

Massol, F. and S. Petit. 2013. Interaction networks in agricultural landscape mosaics. Advances in Ecological Research 49:291-338.

May, R. M. 1972. Will a large complex system be stable? Nature 238:413-414.

Menge, B. A., T. C. Gouhier, S. D. Hacker, F. Chan, and K. J. Nielsen. 2015. Are meta-ecosystems organized hierarchically? A model and test in rocky intertidal habitats. Ecological Monographs 85:213-233.

Metz, J. A. J., T. J. de Jong, and P. G. L. Klinkhamer. 1983. What are the advantages of dispersing; a paper by Kuno explained and extended. Oecologia 57:166-169.

Meynard, C. M., V. Devictor, D. Mouillot, W. Thuiller, F. Jiguet, and N. Mouquet. 2011. Beyond taxonomic diversity: how do $\alpha, \beta$ and $\gamma$ components of functional and phylogenetic diversity respond to environmental gradients? Global Ecology and Biogeography.

Morton, R. D. and R. Law. 1997. Regional species pools and the assembly of local ecological communities. Journal of Theoretical Biology 187:321-331.

Mougi, A. and M. Kondoh. 2016. Food-web complexity, meta-community complexity and community stability. Scientific Reports 6:24478.

Mouquet, N., D. Gravel, F. Massol, and V. Calcagno. 2013. Extending the concept of keystone species to communities and ecosystems. Ecology Letters 16:1-8. 
Mouquet, N. and M. Loreau. 2002. Coexistence in metacommunities: The regional similarity hypothesis. American Naturalist 159:420-426.

Mouquet, N. and M. Loreau. 2003. Community patterns in source-sink metacommunities. American Naturalist 162:544-557.

Mouquet, N., T. E. Miller, T. Daufresne, and J. M. Kneitel. 2006. Consequences of varying regional heterogeneity in source-sink metacommunities: a mechanistic model. Oikos 113:481-488.

Mouquet, N., J. L. Moore, and M. Loreau. 2002a. Plant species richness and community productivity: why the mechanism that promotes coexistence matters. Ecology Letters 5:56-65.

Mouquet, N., J. L. Moore, and M. Loreau. 2002b. Plant species richness and community productivity: why the mechanism that promotes coexistence matters. Ecology Letters 5:56-65.

Muehlbauer, J. D., S. F. Collins, M. W. Doyle, and K. Tockner. 2014. How wide is a stream? Spatial extent of the potential "stream signature" in terrestrial food webs using meta-analysis. Ecology 95:44-55.

Munoz, F., C. Violle, and P.-O. Cheptou. 2016. CSR ecological strategies and plant mating systems: outcrossing increases with competitiveness but stress-tolerance is related to mixed mating. Oikos:n/a-n/a.

Naiman, J. R., E. R. Bilby, E. D. Schindler, and M. J. Helfield. 2002. Pacific Salmon, Nutrients, and the Dynamics of Freshwater and Riparian Ecosystems. Ecosystems 5:399-417.

Nakano, S. and M. Murakami. 2001. Reciprocal subsidies: Dynamic interdependence between terrestrial and aquatic food webs. Proceedings of the National Academy of Sciences of the United States of America 98:166-170.

Nee, S., N. Colegrave, S. A. West, and A. Grafen. 2005. The illusion of invariant quantities in life histories. Science 309:1236-1239.

Neutel, A.-M. and M. A. S. Thorne. 2014. Interaction strengths in balanced carbon cycles and the absence of a relation between ecosystem complexity and stability. Ecology Letters 17:651661.

Niitepõld, K. and I. Hanski. 2013. A long life in the fast lane: positive association between peak metabolic rate and lifespan in a butterfly. Journal of Experimental Biology 216:1388-1397.

Niitepõld, K., A. D. Smith, J. L. Osborne, D. R. Reynolds, N. L. Carreck, A. P. Martin, J. H. Marden, O. Ovaskainen, and I. Hanski. 2009. Flight metabolic rate and Pgi genotype influence butterfly dispersal rate in the field. Ecology 90:2223-2232.

Nogales, M., R. Heleno, B. Rumeu, A. González-Castro, A. Traveset, P. Vargas, and J. M. Olesen. 2015. Seed-dispersal networks on the Canaries and the Galápagos archipelagos: interaction modules as biogeographical entities. Global Ecology and Biogeography:n/a-n/a.

Norberg, J., D. P. Swaney, J. Dushoff, J. Lin, R. Casagrandi, and S. A. Levin. 2001. Phenotypic diversity and ecosystem functioning in changing environments: A theoretical framework. Proceedings of the National Academy of Sciences of the United States of America 98:11376-11381.

O'Connor, M. I., J. F. Bruno, S. D. Gaines, B. S. Halpern, S. E. Lester, B. P. Kinlan, and J. M. Weiss. 2007. Temperature control of larval dispersal and the implications for marine ecology, evolution, and conservation. Proceedings of the National Academy of Sciences 104:12661271.

Ojanen, S. P., M. Nieminen, E. Meyke, J. Pöyry, and I. Hanski. 2013. Long-term metapopulation study of the Glanville fritillary butterfly (Melitaea cinxia): survey methods, data management, and long-term population trends. Ecology and Evolution 3:3713-3737.

Ott, D., C. Digel, B. C. Rall, M. Maraun, S. Scheu, and U. Brose. 2014. Unifying elemental stoichiometry and metabolic theory in predicting species abundances. Ecology Letters:n/a-n/a.

Otto, S. B., B. C. Rall, and U. Brose. 2007. Allometric degree distributions facilitate food-web stability. Nature 450:1226-1229. 
Pillai, P., A. Gonzalez, and M. Loreau. 2011. Metacommunity theory explains the emergence of food web complexity. Proceedings of the National Academy of Sciences 108:19293-19298.

Pillai, P., A. Gonzalez, and M. Loreau. 2012. Evolution of dispersal in a predator-prey metacommunity. American Naturalist 179:204-216.

Polis, G. A., W. B. Anderson, and R. D. Holt. 1997. Toward an integration of landscape and food web ecology: The dynamics of spatially subsidized food webs. Annual Review of Ecology and Systematics 28:289-316.

Polis, G. A. and S. D. Hurd. 1995. Extraordinarily high spider densities on islands: Flow of energy from the marine to terrestrial food webs and the absence of predation. Proceedings of the National Academy of Sciences of the United States of America 92:4382-4386.

Pulliam, H. R. 1988. Sources, sinks, and population regulation. American Naturalist 132:652-661.

Réale, D., D. Garant, M. M. Humphries, P. Bergeron, V. Careau, and P.-O. Montiglio. 2010. Personality and the emergence of the pace-of-life syndrome concept at the population level. Philosophical Transactions of the Royal Society of London B: Biological Sciences 365:4051-4063.

Reznick, D., M. Bryant, and D. Holmes. 2006. The evolution of senescence and post-reproductive lifespan in guppies (Poecilia reticulata). PLoS Biology 4:136-143.

Ronce, O. 2007. How does it feel to be like a rolling stone? Ten questions about dispersal evolution. Annual Review of Ecology, Evolution, and Systematics 38:231-253.

Ronce, O. and J. Clobert. 2012. Dispersal syndromes. Pages 119-138 in J. Clobert, M. Baguette, T. G. Benton, and J. M. Bullock, editors. Dispersal Ecology and Evolution. Oxford University Press, Oxford.

Schindler, D. E. and M. D. Scheuerell. 2002. Habitat coupling in lake ecosystems. Oikos 98:177-189.

Seagle, S. W. 2003. Can ungulates foraging in a multiple-use landscape alter forest nitrogen budgets? Oikos 103:230-234.

Seymour, M., E. A. Fronhofer, and F. Altermatt. 2015. Dendritic network structure and dispersal affect temporal dynamics of diversity and species persistence. Oikos 124:908-916.

Shen, W., Y. Lin, G. D. Jenerette, and J. Wu. 2011. Blowing litter across a landscape: effects on ecosystem nutrient flux and implications for landscape management. Landscape Ecology 26:629-644.

Shmida, A. and M. V. Wilson. 1985. Biological determinants of species diversity. Journal of Biogeography 12:1-20.

Sitters, J., C. L. Atkinson, N. Guelzow, P. Kelly, and L. L. Sullivan. 2015. Spatial stoichiometry: crossecosystem material flows and their impact on recipient ecosystems and organisms. Oikos:n/a-n/a.

Smeti, E., D. L. Roelke, and S. Spatharis. 2016. Spatial averaging and disturbance lead to high productivity in aquatic metacommunities. Oikos 125:812-820.

Staddon, P., Z. Lindo, P. D. Crittenden, F. Gilbert, and A. Gonzalez. 2010. Connectivity, non-random extinction and ecosystem function in experimental metacommunities. Ecology Letters 13:543-552.

Sterner, R. W. and J. J. Elser. 2002. Ecological Stochiometry: the biology of elements from molecules to the biosphere. Princeton University press, Princeton.

Strathmann, R. R. 1985. Feeding and Nonfeeding Larval Development and Life-History Evolution in Marine Invertebrates. Annual Review of Ecology and Systematics 16:339-361.

Tilman, D. 1980. Resources: A graphical-mechanistic approach to competition and predation. The American Naturalist 116:362-393.

Tilman, D. 1982. Resource Competition And Community Structure. Princeton University Press, Princeton.

Tilman, D. 1985. The resource-ratio hypothesis of plant succession. American Naturalist:827-852.

Tilman, D. 1988. Plant Strategies and the Dynamics and Structure of Plant Communities.(MPB-26). Princeton University Press. 
Travis, J. M. J. 2001. The color of noise and the evolution of dispersal. Ecological Research 16:157163.

Travis, J. M. J., S. C. F. Palmer, S. Coyne, A. Millon, and X. Lambin. 2013. Evolution of predator dispersal in relation to spatio-temporal prey dynamics: how not to get stuck in the wrong place! PLOS ONE 8:e54453.

Vanni, M. J. 2002. Nutrient Cycling by Animals in Freshwater Ecosystems. Annual Review of Ecology and Systematics 33:341-370.

Venail, P. A., R. C. MacLean, T. Bouvier, M. A. Brockhurst, M. E. Hochberg, and N. Mouquet. 2008. Diversity and productivity peak at intermediate dispersal rate in evolving metacommunities. Nature 452:210-U257.

Vitalis, R., F. Rousset, Y. Kobayashi, I. Olivieri, and S. Gandon. 2013. The joint evolution of dispersal and dormancy in a metapopulation with local extinctions and kin competition. Evolution 67:1676-1691.

Volkov, I., J. R. Banavar, S. P. Hubbell, and A. Maritan. 2003. Neutral theory and relative species abundance in ecology. Nature 424:1035-1037.

Weider, L. J., W. Makino, K. Acharya, K. L. Glenn, M. Kyle, J. Urabe, and J. J. Elser. 2005. Genotype $\times$ environment interactions, stoichiometric food quality effects, and clonal coexistence in Daphnia pulex. Oecologia 143:537-547.

Wieters, E. A., S. D. Gaines, S. A. Navarrete, C. A. Blanchette, and B. A. Menge. 2008. Scales of dispersal and the biogeography of marine predator-prey interactions. The American Naturalist 171:405-417.

Wolf, M. and F. J. Weissing. 2012. Animal personalities: consequences for ecology and evolution. Trends in Ecology \& Evolution 27:452-461.

Yachi, S. and M. Loreau. 1999. Biodiversity and ecosystem productivity in a fluctuating environment: The insurance hypothesis. Proceedings of the National Academy of Sciences of the United States of America 96:1463-1468. 


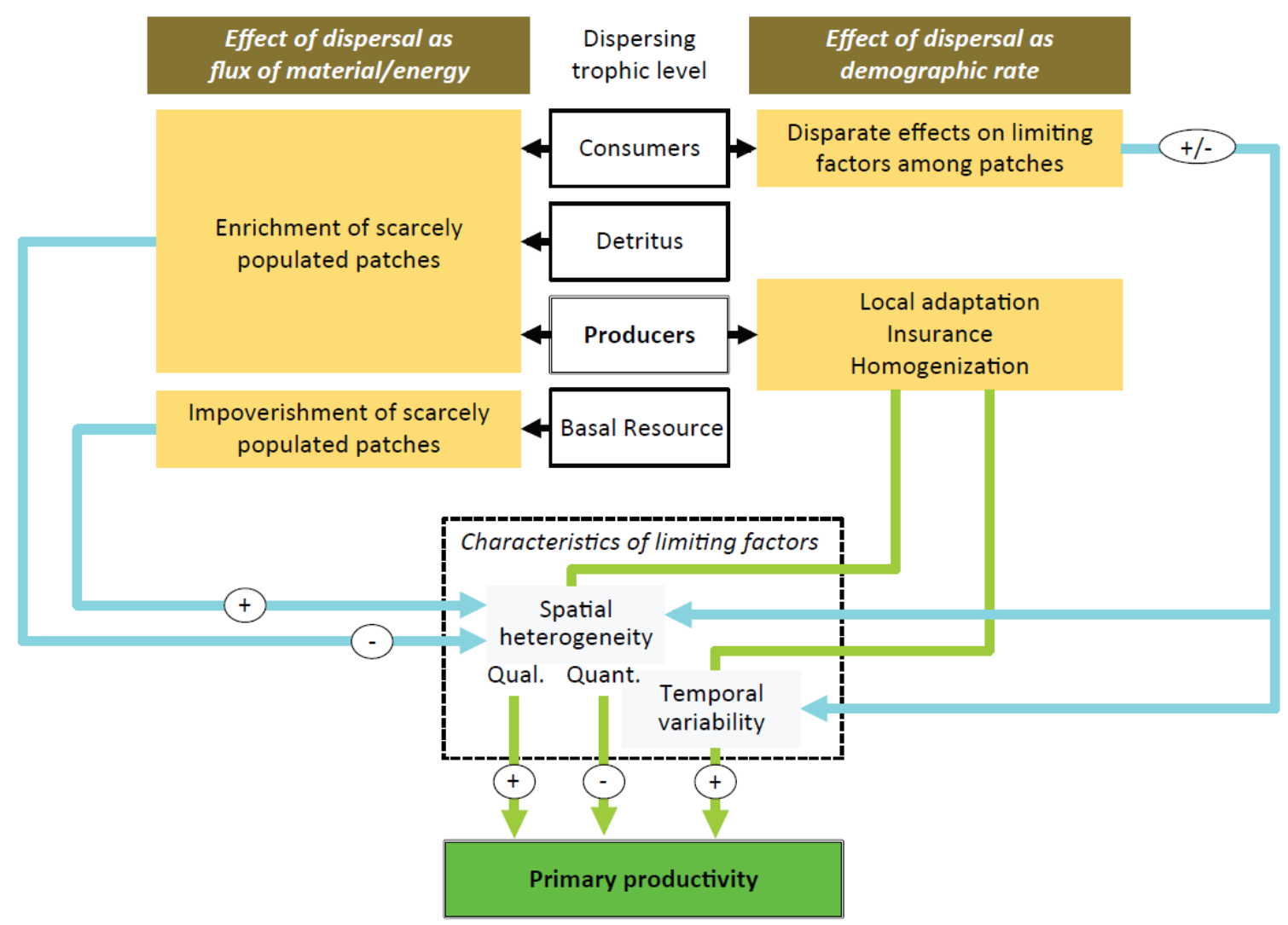

937

Fig. 1 - Links between dispersal and primary productivity according to meta-ecosystem theory (Loreau et al. 2003a, Mouquet and Loreau 2003, Gravel et al. 2010a). On the left-hand side of the diagram, dispersal of consumers, detritus and producers, seen as fluxes of material and energy, tends to increase the amount of biomass in scarcely populated patches (i.e. those in which basal resource levels are too low for the establishment of producers and/or consumers) and thus, through nutrient recycling, to decrease the spatial heterogeneity in nutrient stocks among patches (low blue arrow with a minus sign). Diffusion of the basal resource, nutrients (Gounand et al. 2014), or producers seen as basal resource (Pedersen et al. 2016), on the other hand, will create a source-sink movement from low-productivity patches to already highly productive patches, thus aggravating the spatial heterogeneity of resource stocks among patches (long blue arrow with a plus sign). Spatially heterogeneous distribution of a single resource results in a negative effect on primary productivity (quantitative heterogeneity). However, in case of several resources, heterogeneity in local nutrient balances (qualitative heterogeneity) may lead to positive effects on productivity (Marleau et al. 2015). On the right-hand side of the diagram, dispersal of primary producers seen as a demographic rate (i.e. the I and $E$ of the BIDE framework proposed by Pulliam 1988) generally decreases local adaptation of primary producers (they end up in patches in which they are less well adapted, but see Edelaar and Bolnick 2012 for possible counter-examples), but primary productivity provided by the community of primary producers gains "insurance" against temporal variability of the environment. Dispersal thus increases productivity at the regional scale when the environment is temporally variable, but decreases it when it is spatially heterogeneous (green arrows going through spatial heterogeneity and spatial variability of limiting factors); the combination of the two results in a hump-shaped link between dispersal and productivity. The blue arrows on the right-hand side of the diagram represent the potential demographic effects of consumer dispersal on limiting factor variability in time and space; as this effect is quite variable across scenarios, its effect on productivity is far from being predictable (Jansen 1995, 2001, Koelle and Vandermeer 2005, Gounand et al. 2014). 

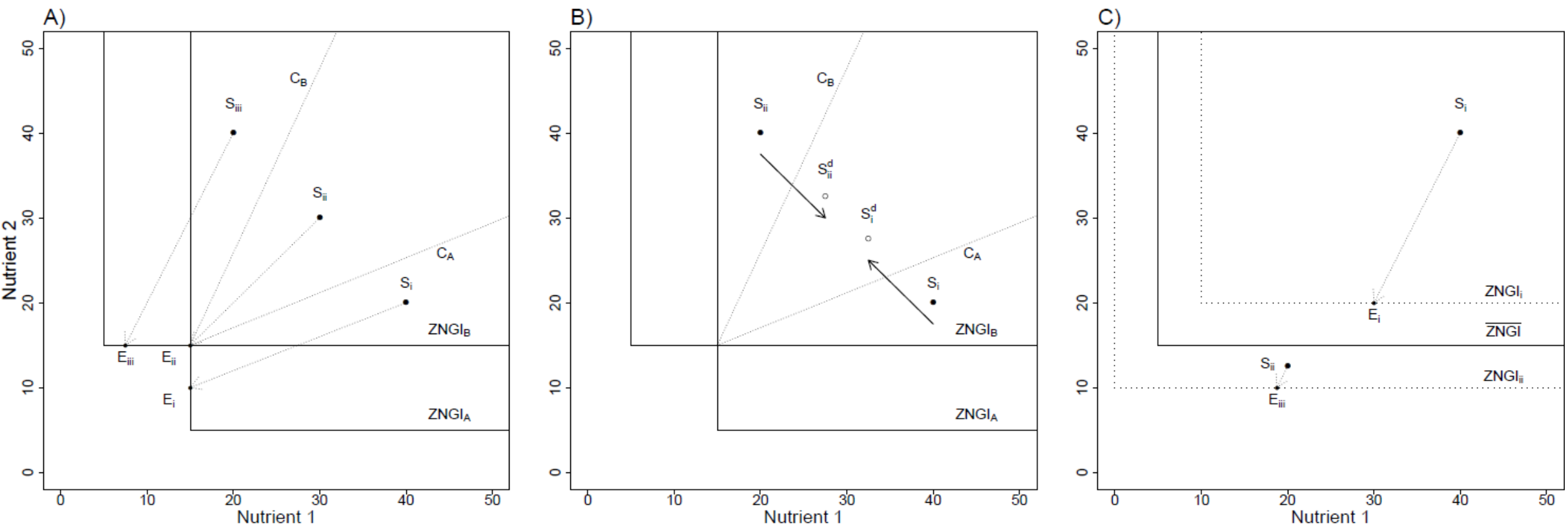

Fig. 2 - Graphical interpretation of the resource-ratio theory in a competitive meta-ecosystem. A) Representation of a single ecosystem made of two resources and two competitors. Stable coexistence will depend on where the supply point $S_{i}$ is located relative to the projection of the consumption vectors $C_{A}$ and $C_{B}$. Equilibrium nutrient availability is indicated by the $E_{i}$ and the location depends on the final species composition. $B$ ) Conceptual representation of source-sink dynamics of inorganic nutrients in a two-patch meta-ecosystem. The location of the two supply points is moved toward the centre of the nutrient space, to locations $S_{i}^{*}$, resulting in the homogenization of the metacommunity. Regional coexistence is possible in absence of nutrient movement, but not local coexistence. The movement of net supply points toward the centre, however, allows local coexistence of the two species. C) Representation of the effect of dispersal of a single species on the location of the ZNGIs in presence of source-sink dynamics. The ZNGI moves to the bottom left in the patch ii (a sink), because of immigration, allowing its stable persistence there. Similarly, the ZNGI moves to the top right in patch $\mathrm{i}$ (a source), consequent to emigration. 


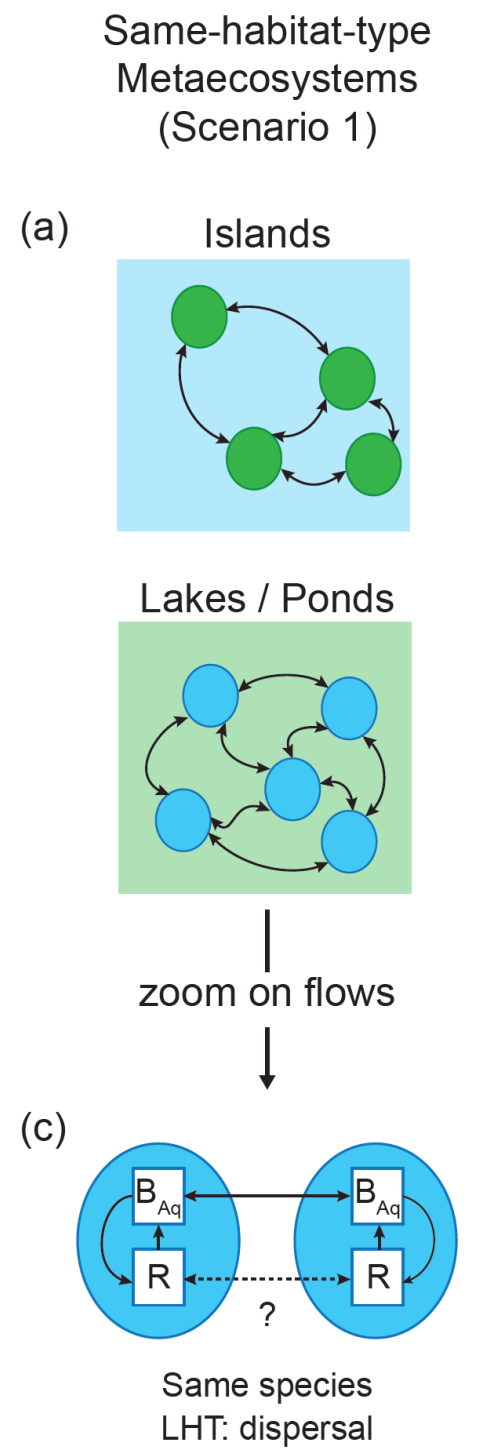

\section{Different-habitat-type Metaecosystems (Scenario 2)}

(b)

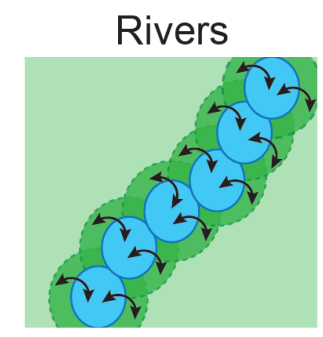

Lakes / Ponds

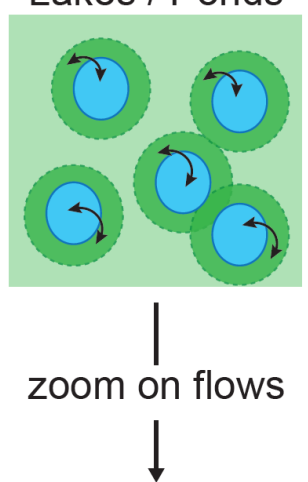

(d)

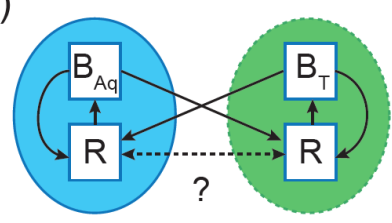

Different species

LHT: phenology, life span (death)
Fig. 3 - Two contrasting meta-ecosystem types based on empirical observations and illustrated by aquatic - terrestrial landscapes. Panels (a) and (b) give examples of spatially structured landscapes in which habitat patches are connected by spatial flows (arrows). Blue and green colours refer to aquatic and terrestrial respectively. Left column shows meta-ecosystems in which patches are of same habitat type, while right column shows meta-ecosystems in which patches are of different habitat types. If we zoom on documented flows between two patches (bottom panels), same-habitat-type meta-ecosystems (c) are mostly linked by organism dispersal and potential flows of resource (R), but these are poorly documented (dotted arrows). Differenthabitat-type meta-ecosystems (d) are linked by exchanges of dead organisms fuelling the resource pool. $\mathrm{B}_{\mathrm{Aq}}$, and $\mathrm{B}_{\mathrm{T}}$ refer to biomass of aquatic and terrestrial organisms respectively. 


\section{BOX 1: GLOSSARY}

Ecological stoichiometry: The study of element (e.g. carbon, nitrogen, phosphorus...) content within organisms and its stocks and fluxes involved in ecological processes at larger scales.

Keystone and burden ecosystems: An ecosystem is said to be "keystone" if its removal from the meta-ecosystem leads to disproportionately deleterious consequences for a given (or several) ecosystem property (e.g. productivity) at the meta-ecosystem scale. Conversely, a burden ecosystem's removal leads to disproportionately beneficial consequences at the meta-ecosystem scale. The definition of "disproportionately" in this context is based on what the removal of a typical ecosystem of the same "size" would entail at the meta-ecosystem scale (Mouquet et al. 2013).

Metabolic theory of ecology: A theory which links the different rates involved in organism life 1000 history (growth, consumption, death, etc.) with body size and temperature through chemical and physical processes and laws (Brown et al. 2004).

1002

Neutral theory of community ecology: A theory which explains the diversity of species observed in ecological communities solely through the interplay of stochastic processes (dispersal, ecological drift, speciation, remote colonization) and not through species niche (Hubbell 2001).

1005

1006

1007

1008

1009

1010

1011

1012

1013

1014

1015

1016

1017

"Pace-of-life" theory of animal personality syndromes: A theory which posits that natural selection generally leads to the existence of general personality syndromes linking physiological, immunological, foraging and life-history traits (Réale et al. 2010).

Resource ratio theory: A theory which explains the coexistence of species based on the complementarity of their resource needs and their impacts on resource stocks (León and Tumpson 1975, Tilman 1980, 1982). This theory has been expanded since then to include other limiting factors, such as predator pressure (Leibold 1995). 


\section{BOX 2: DISPERSAL AND STOICHIOMETRY IN META-ECOSYSTEMS}

The resource-ratio theory of plant coexistence (Tilman 1982, 1988), based on the seminal model of León and Tumpson (1975), has been instrumental in our understanding of the intimate linkage between stoichiometry, community assembly and ecosystem functioning. The theory applies to two resources the $\mathrm{R}^{*}$ principle of competition theory. Its main prediction is that stable coexistence between two species requires a particular ratio of the two limiting nutrients. Owing to its accessible graphical representation, the theory has a central position in most ecological textbooks (e.g. Begon et al. 2006). The theory was also further developed to derive a vast array of secondary predictions, such as the impact of resource heterogeneity and fertilization on species richness and successional dynamics (Tilman 1982, 1985). The resource ratio theory builds on the idea that spatial heterogeneity in the ratio of limiting resources promotes the maintenance of highly diverse communities (Tilman 1982). This prediction does apply to various spatial scales, from the individual-to-individual variation in soil properties, to landscape variations. The theory does not, however, consider the impact of spatial exchanges of plants, nutrients and other materials between localities. Both metacommunity (Mouquet and Loreau 2002, Abrams and Wilson 2004) and meta-ecosystem (Gravel et al. 2010a) theories in source-sinks settings have shown that the outcome of competitive interactions could be significantly altered by these flows. While it is quite challenging to elaborate a full and comprehensive theory for stoichiometry of nutrient flows in source-sink meta-ecosystems, it is nonetheless possible to get some intuition from a graphical representation of two patches and two nutrients.

The graphical interpretation of the resource-ratio theory builds on a few important concepts. First, the Zero Net Growth Isocline (ZNGI) represents the combination of the two nutrient concentrations resulting in a null intrinsic growth rate for a given species (Fig. 2). In other words, it is the two-dimensional representation of the $\mathrm{R}^{*}$ principle of competition theory. Nutrients are supplied at a given ratio in any locality, owing to processes such as atmospheric depositions on land and river and stream inflows in lakes. In absence of consumption by primary producers, the nutrients do equilibrate to a given concentration and ratio, represented visually as the supply point S (Fig. 2). A key concept is that a species is able to persist provided that the supply point is located somewhere above its ZNGI. Once a species establishes, it consumes nutrients in a given ratio, which is represented by the consumption vector (the slope of the vector corresponds to the ratio of nutrient consumption). The system will converge at equilibrium to the point corresponding to the intersection between the $\mathrm{ZNGI}$ and the consumption vector aligned on the supply point. Coexistence of two species occurs provided that their ZNGls do cross each other, and that the supply point is located in the triangle defined by the projection of their respective consumption vectors (Fig. 2; Tilman 1982, 1988). When limiting factors are not resources, but natural enemies (i.e. the case in models of apparent competition), the same approach can also be used (Leibold 1995, Grover and Holt 1998), although ZNGIs and the conclusions associated with the different angles of intersections are not defined in exactly the same way, and nonlinearities in predator functional responses can lead to departures from resource-ratio theory (Grover and Holt 1998).

Nutrient cycling and any spatial exchange of nutrients between localities, whether inorganic or sequestered in biomass, significantly complicate the situation and often make the underlying mathematics intractable. But fortunately, the concept is pretty straightforward to illustrate graphically. In both cases, they represent an additional source of nutrient inputs and therefore move the supply point in the two-nutrient space. In the simple case of decomposition of detritus, where both nutrients are mineralized at the same rate, we do find the net supply point $\left(\mathrm{S}^{\prime}\right)$ moving away from its original location. It increases the fertility of the system, but does not change the equilibrium situation because it keeps the same ratio. The net supply point will, however, move in one direction or another if the mineralization or the dispersal between 
localities does not respect the ratio at which it is consumed. For mineralization to alter the conditions for coexistence, it requires that the net supply point $S^{\prime}$ is located within the projection of the two consumption vectors (Daufresne and Hedin 2005).

The situation is slightly more complicated for nutrient diffusion, in particular when the two localities do have different nutrient supplies, or alternatively if they are occupied by different species with distinct ZNGIs and consumption vectors. If the movement of nutrients is passive, it will move by diffusion from the locality that has the highest nutrient concentration (the source) to the locality with the lowest nutrient concentration (the sink). The location of the net supply point will therefore move in both localities. If the two localities are occupied by the same species, it will inevitably move the supply point toward the centre of the nutrient space, as it will homogenize the meta-ecosystem. It could, however, go in the other direction depending on the characteristics of each species inhabiting localities. As a consequence, each nutrient in a patch could thus either increase or decrease in availability, thus eventually affecting the conditions for coexistence.

Finally, organisms themselves can move across the patches. The impact of their dispersal has been extensively studied in a wide range of conditions (e.g. Amarasekare and Nisbet 2001, Mouquet and Loreau 2002, Abrams and Wilson 2004). Again, often the mathematics is hard to track in all of these models, but the graphical representation provides a useful and general understanding of the consequences of source-sink dynamics on species coexistence. Basically, dispersal inflicts an increased loss of individuals in the location with highest density (emigration from the source), and an enrichment in the location with lowest density (immigration to the sink). It provokes a translation of ZNGIs for both nutrients (Fig. 2), moving them to higher values in the source location and to lower values in the sink. As a consequence, dispersal might sustain a population in a location that would be otherwise inhospitable, as in traditional source-sink systems (Pulliam 1988) or in competitive systems (Mouquet and Loreau 2002). The projection of the consumption vectors will not be altered by dispersal of the organisms, even if there is nutrient cycling of their detritus, except in the case in which the two nutrients are not recycled at the same rate.

In conclusion, spatial exchanges of nutrients, organisms and their detritus might alter the conditions for coexistence. They tend to promote regional coexistence in presence of spatial heterogeneity of supply points because (i) the supply point moves toward the centre of the nutrient space, thereby making the conditions for coexistence more likely, and (ii) the ZNGls move in a way that increases the tolerance of species to harsh conditions and decreases their performance in good locations. More extensive analyses also show that it can lead to alternative stable states, and potentially dynamic instabilities (Daufresne and Hedin 2005; Gravel et al., unpublished manuscript). Another consequence is that dispersal, of all kinds, tends to homogenize the meta-ecosystem in most situations. 